\title{
Assessment of exercise capacity in African patients with chronic heart failure using six minutes walk test
}

This article was published in the following Dove Press journal:

International Journal of General Medicine

24 February 2010

Number of times this article has been viewed

\author{
Rufus A Adedoyin' \\ Samuel A Adeyanju² \\ Michael O Balogun ${ }^{3}$ \\ Anthony O Akintomide ${ }^{3}$ \\ Rasaaq A Adebayo ${ }^{3}$ \\ Patience O Akinwusi ${ }^{4}$ \\ Taofeek O Awotidebe' \\ 'Department of Medical Rehabilitation, \\ Obafemi Awolowo University, Ile-Ife, \\ Nigeria; ${ }^{2}$ Department of Physical \\ and Health Education, Obafemi \\ Awolowo University, Ile-Ife, Nigeria; \\ ${ }^{3}$ Department of Medicine, Obafemi \\ Awolowo University, Ile-Ife, Nigeria; \\ ${ }^{4}$ Department of Medicine, Ladoke \\ Akintola University of Technology, \\ Osogbo, Nigeria
}

Background: The purpose of this study was to assess the functional capacity during a 6-minute corridor walk and a 6-minute bicycle ergometry exercise in patients with chronic heart failure (CHF).

Method: Thirty five patients with stable CHF were recruited for the study. Each subject performed six minutes corridor walk and 6-minute bicycle ergometry testing. The 6-minute walk required the subjects to walk at a self selected speed on a 20 meter marked level ground for 6-minute. All the subjects also performed a 6-minute exercise on a stationary bicycle ergometer with initial resistance of 20 watts and increased by 10 watts after 3 -minutes. The perceived rate of exertion was assessed using a modified Borg Scale after each exercise mode. The maximum oxygen consumption was derived using American College of Sport Medicine equations.

Results: Result showed high positive correlation between distance walked in the 6-minute and the maximum volume of oxygen $\left(\mathrm{VO}_{2} \max \right)(\mathrm{r}=0.65, P<0.01)$. The average distance walked was $327 \mathrm{~m} \pm 12.03 \mathrm{~m}$. The $\mathrm{VO}_{2}$ max estimated during bicycle ergometry was higher $(13.7 \pm$ $1.9 \mathrm{~L})$ than during the six minutes walk $(8.9 \pm 1.2 \mathrm{~L})$.

Conclusion: Six minutes walk could be useful to evaluate exercise tolerance in patients with chronic heart failure, while the bicycle ergometer could be more appropriate in the assessment of maximum functional capacity in these patients.

Keywords: 6-minute walk, CHF, bicycle ergometer

\section{Introduction}

Evidence has shown that hemodynamic variables at rest or during exercise are known to not correlate with symptoms or exercise capacity in patients with heart failure. ${ }^{1,2}$ Thus, symptoms are a poor guide in the evaluation of the severity of incapacitance in heart failure patients. ${ }^{3}$

Different tests are now available for the evaluation of functional capacity in these patients. These include a cardiopulmonary exercise test, 6-minute walk, and 15 step exercise oximetry test. ${ }^{4,5}$

The selection of an appropriate test and protocol for assessing functional capacity is of critical importance. The established objective and reproducible method is the measurement of respiratory gas exchange during a maximal exercise test. ${ }^{6}$ But because of the expensive nature of this method, simpler methods are now being used for clinical purpose.

Six minutes corridor walk has been widely reported to be a good method of assessing functional capacity. ${ }^{7}$ The six minute walk test however requires a corridor that is temperature controlled. Many experts now make use of self-powered treadmill for the 
6- and 12-minute walking tests, to overcome the problem of corridor walk. ${ }^{8}$

In developing nations where there is erratic power supply, a powered treadmill might not be realistic. Cycle ergometers, that are less expensive, are commonly used for exercise in Nigeria. Cycle ergometry is usually preferred in subjects with gait instability or when simultaneous imaging is planned. ${ }^{9}$ Studies have shown a consistent relationship between aerobic capacity on a treadmill and a cycle ergometer. ${ }^{10}$ Our study was designed to assess the functional capacity of heart failure patients using a 6-minute corridor walk and bicycle ergometer.

\section{Methodology Subjects}

Thirty-five patients with congestive heart failure, who were receiving treatment in the cardiac care unit of Obafemi Awolowo University Teaching Hospitals Complex, Ile-Ife (OAUTHC) were recruited for the study. Patients were examined and referred by cardiologists before being included in the study. All patients signed an informed consent form before being eligible for the study and the study protocol was approved by the OAUTHC Ethics Committee. The mean ( \pm standard deviation $[S D]$ ) left ventricular ejection fraction of these patients (assessed by M-mode/2 dimensional transthoracic echocardiography) was $35 \pm 10.8$. All the patients were placed on diuretics (frusemide), digitalis (digoxin), and angiotensin converting enzyme inhibitors (ACE) (lisinopril or enalapril). A few of the patients that experienced a dry cough were changed from ACE inhibitors to the angiotensin receptor blocker (valsatan).

\section{Inclusion criteria}

Patients was recruited if he or she could be classified as being class II or III, in the New York Heart Association (NYHA) stages of heart failure, was in sinus rhythm, and was able to perform exercise testing. Thirty-five CHF patients that satisfied the inclusion criteria were enrolled for the study using repeated measure experimental protocol (ie, patient served as his or her own control).

\section{Exclusion criteria}

A patient was excluded if he or she had any of the following conditions: history or sign of significant respiratory disease; severe mitral regurgitation and other severe valvular diseases; angina pectoris; or an inability to walk without physical assistance.

\section{Procedure}

On the first visit, each subject's age, height and weight were recorded. The height was measured with subject standing with shoes off and the heels, the back, occiput touching the measure and with subject looking straight ahead. The weight was measured with the subject standing erect on a weighing scale with the shoes off.

The procedure of the exercise was then explained to the subjects. They were told that they were not under any obligation to complete the study and if they experienced symptoms such as: shortness of breath; fatigue or discomfort, during the exercise the test would be terminated. All subjects had a demonstration on the bicycle ergometer for familiarization and were given oral instructions with respect to exercise testing. They were requested to avoid nonessential physical work and strenuous exercise on the day before the testing. Furthermore, they were requested not to smoke, or drink alcohol, or coffee on the day of the exercise test. Subsequently, all the subjects were introduced to the modified Borg scale for rating perceived physical exertion. In the scale 0 represents no exertion; 5 represents moderate exertion and 10 represents extreme exertion.

Prior to the commencement of the testing, patients were assessed during a 2-week period in which echocardiography, electrocardiography and symptom-limited cardiopulmonary graded exercise were performed for familiarization purposes and for characterization of exercise disability.

The two modes of exercises testing; bicycle ergometry and the self-paced corridor walk were randomized. For each subject, all the testing was completed within a week. The test was terminated at the patient's request, on symptom-limited exercise or after 6-minute of corridor walk. A physician who was familiar with the study protocol supervised the test. Cardiopulmonary equipments, including defibrillator and cardiac emergency drugs were made available in the exercise laboratory, in case of emergency.

\section{Six minutes walk test}

A 20-metre enclosed corridor within the cardiac care unit of the hospital was marked out for the test. Subjects were allowed to rest for a period of 10 minutes in sitting position before the commencement of exercise test.

Patients were instructed to walk from the starting point to the end at their own selected pace while attempting to cover as much ground as possible in six minutes. They were encouraged every 30 seconds or so in a standardized manner by saying: "You are doing well" or "Keep up the good work". After six minutes, the distance covered was measure 
to the nearest metre. Patients were then asked to rate his or her exertion level using the modified Borg scale.

\section{Bicycle ergometer}

The bicycle ergometry test started with the patient sitting on the bicycle with initial resistance of 20 watts that was increased by 10 watts after 3 minutes. The 6 -minute ride is reported to be similar to the work of the 6-minute walk. ${ }^{11}$ To overcome the inertial of the flywheel; the pedals were driven manually by a staff at $60 \mathrm{rpm}$ at the start of the 6-minute ride. The patients were asked to maintain the 60 revolutions per minute throughout the test.

Maximum oxygen consumption $\left(\mathrm{VO}_{2} \max \right)$ was calculated using equations derived by American College of Sport Medicine equations: ${ }^{12}$

Level walking: $\mathrm{VO}_{2}(1 \mathrm{mLO} 2 \mathrm{~kg} / \mathrm{min})$ $=$ Speed $(\mathrm{m} / \mathrm{min}) \times 0.1 \mathrm{~m} / \mathrm{O}_{2} / \mathrm{kg}+3.5 \mathrm{~m} / \mathrm{O}_{2} / \mathrm{kg} / \mathrm{min}$

Cycle ergometry: Total $\mathrm{VO}_{2}$ $=\mathrm{kg} / \mathrm{m} \times 2 \mathrm{~mL} / \mathrm{O}_{2} / \mathrm{min}+3.5 \mathrm{mO}_{2} \times$ body wt $(\mathrm{kg} / \mathrm{min})$.

\section{Analysis}

Data were summarized by computing the means, standard deviations (SDs), and percentages as appropriate. The correlation coefficient was used to relate anthropometric characteristics with distance walked, maximum oxygen consumption and energy expenditure. Where a significant difference was found, Scheffe Post hoc analysis was used to probe the difference.

Furthermore, a t-test was used to compare the level of exertion after the exercise. Regression analysis was used to generate equation to predict $\mathrm{VO}_{2}$ max and energy expenditure in each of the exercise modes as appropriate. All analyses were performed with the SPSS Statistical Package Software Version 11.0 (SPSS, Chicago, IL, USA).

\section{Results}

\section{Physical characteristics of the subjects}

The physical characteristics of the subjects are presented in Table 1 . The study population contained 35 patients;
19 women and 16 men. The mean age of the population was 56.95 years \pm 15.05 years and ranged between 22 and 87 years. Using NYHA classification 21 patients were diagnosed as having class III while the remaining 14 patients were class II.

Men were found to be heavier, older and taller than women, though no significant differences were recorded when t-test was computed $(P>0.05)$. The causes of CHF recorded in this study ranged from, hypertensive heart failure $(n=25)$; dilated cardiomyopathy $(\mathrm{n}=8)$; or unknown $(\mathrm{n}=2)$.

The results of the t-test showed that the levels of $\mathrm{VO}_{2}$ max, perceived physical exertion and energy expenditure were higher during bicycle ergometry than the 6-minute walk at $(P<0.001$ Table 2$)$. A close correlation was found between distance walked and $\mathrm{VO}_{2}(\mathrm{r}=0.65, P<0.001$ Table 3). A linear regression equation to predict $\mathrm{VO}_{2} \max$ was fitted to this model:

$\mathrm{VO}_{2} \max (\mathrm{mL} / \mathrm{kg} /$ minute $)=5.598+0.0105 \times 6$-minute walk(m).

\section{Discussion}

Exercise prescriptions and encouraging patients with CHF to exercise can have a significant impact on the management of symptoms as well the quality of life of patients. Functional assessment is usually recommended in order to make the exercise safe for the patients.

In this study the distance walked in 6-minute was found to correlate with $\mathrm{VO}_{2}$ max. A similar result was reported among patients with CHF by Morales and colleagues ${ }^{14}$ They reported that both the shuttle walk test (SWT) and the 6-minute walk correlated with $\mathrm{VO}_{2}(\mathrm{r}=0.83, P<0.001$ and $\mathrm{r}=0.69, P<0.001$ respectively).

Among several methods of assessing functional capacity the 6-minute walk test is probably the most widespread. The relationship between $\mathrm{VO}_{2}$ max and distance traveled during the 6-minute walk in this study is similar to that reported by Cahalin and colleagues. ${ }^{13}(r=0.65$ versus 0.64 respectively).

Table I Physical characteristics of the study population

\begin{tabular}{|c|c|c|c|c|}
\hline Variable & Mean \pm SD & Mean \pm SD & Mean \pm SD & $P$ value \\
\hline Gender & Women $(n=19)$ & Men $(n=26)$ & Total $(n=35)$ & \\
\hline Age (years) & $52.3 \pm 16.2$ & $61.6 \pm 13.9$ & $56.95 \pm 15.05$ & 0.134 \\
\hline Height (m) & $1.6 \pm 0.57$ & $1.65 \pm 0.06$ & $1.63 \pm 0.34$ & 0.664 \\
\hline Weight (kg) & $57.56 \pm 12.1$ & $61.06 \pm 11.26$ & $59.31 \pm 11.68$ & 0.356 \\
\hline BMI $\left(\mathrm{kg} / \mathrm{m}^{2}\right)$ & $22.4 \pm 5.1$ & $23.08 \pm 5.2$ & $22.74 \pm 5.15$ & 0.345 \\
\hline
\end{tabular}

Abbreviations: SD, standard deviation; BMI, body mass index. 
Table 2 Result of t-Test comparing the dependent variables $\left(\mathrm{VO}_{2}\right.$ and perceived exertion) during corridor walk and ergometer

\begin{tabular}{llllll}
\hline Variables & $\begin{array}{l}\text { Corridor } \\
\text { walk }\end{array}$ & & $\begin{array}{l}\text { Bicycle } \\
\text { ergometer }\end{array}$ & t & P value \\
\cline { 2 - 3 } \cline { 5 - 6 } & Mean \pm SD & & Mean \pm SD & & \\
\hline $\mathrm{VO}_{2} \max$ & $8.9 \pm 1.2$ & & $13.7 \pm 1.9$ & 13.5 & $0.000 *$ \\
$\begin{array}{l}\text { perceived } \\
\text { exertion }\end{array}$ & $2.3 \pm 3.3$ & & $4.2 \pm 1.1$ & 3.7 & $0.000 *$ \\
\hline
\end{tabular}

Note: *Significant at $P<0.05$.

Abbreviations: $\mathrm{SD}$, standard deviation. $\mathrm{VO}_{2}$ max, maximum volume of oxygen intake.

The average distance covered in this study was (327 m) lower than the one reported by both Lucas and colleagues, and Morales and colleagues ${ }^{11,14}$ with $448 \mathrm{~m}$ and $393 \mathrm{~m}$ respectively. The reasons for the differences might be that the population in the Lucas study ${ }^{11}$ was younger than patients recruited for this study. Furthermore, Morales and colleagues ${ }^{14}$ took the result of the second 6-minute walk performed instead of the first 6-minute walk adopted in this study. Literature has shown that distance walked in 6-minute is slightly increased in successful tests..$^{15,16}$

Although the distance during the SWT is reported to correlate with $\mathrm{VO}_{2}$ max better than distance in 6-minute walk, the SWT is more stressful to patients because it is more strenuous than the 6-minute walk, causing significantly higher values in maximum heart rate, systolic blood pressure and rating of perceived exertion than 6-minute. ${ }^{14} \mathrm{With}$ the 6-minute walk the patient determines the speed of walking and the distance walked will depend on their capacity to pace themselves adequately. While the 6-minute walk is a time limited test the SWT is a symptom limited test. The speed of walking in the SWT is standardized and has to be slightly increased by $0.17 \mathrm{~m} / \mathrm{s}$ at every level. ${ }^{17}$ Patient may therefore find 6-minute test easier to perform than the SWT.

The average $\mathrm{VO}_{2}$ max recorded during the bicycle ergometry was found to be higher than that recorded during walking, $13.7 \mathrm{ml} / \mathrm{kg} /$ minute and $8.9 \mathrm{~mL} / \mathrm{kg} /$ minute respectively.

This experience confirmed that $\mathrm{VO}_{2}$ max predicts survival with heart failure for both bicycle and treadmill

Table 3 Relationship between $\mathrm{VO}_{2}$ max and distance

\begin{tabular}{ll}
\hline Dependent variables & $\begin{array}{l}\text { Pearson product correlation } \\
\text { coefficient }\end{array}$ \\
\hline Age & -0.227 \\
Height & 0.248 \\
Weight & -0.211 \\
Body mass index & -0.211 \\
Distance & $0.647^{* *}$ \\
\hline
\end{tabular}

Note: $* * p<0$ s. protocols. ${ }^{18,19}$ The higher the distance ambulated, the higher the possibility to have a preserved $\mathrm{VO}_{2} \max$. Patients who achieve a distance greater than $450 \mathrm{~m}$ would probably have a peak $\mathrm{VO}_{2}>14 \mathrm{~mL} / \mathrm{kg} /$ minute. ${ }^{14}$ The authors stated that the information might help physicians to make decisions about the management of their patients, including the possibility to defer heart transplantation if there are no other clearly unfavorable prognostic factors.

According to Sullivan and colleagues, ${ }^{20}$ peak $\mathrm{VO}_{2}$ from bicycle ergometer may be 5\% to $11 \%$ lower than for treadmill testing. This present study revealed that $\mathrm{VO}_{2} \max$ in bicycle ergometry is greater by $35 \%$ than walking.

The 6-minute bicycle ride at is reported to be similar to the work of 6-minute walking. ${ }^{11}$ The difference in the aerobic capacity of the two exercise modes may therefore hinge upon different levels of exercise workload.

In contrast, the study of Lucas and colleagues, ${ }^{11}$ in patients with advanced heart failure, suggests that the 6-minute walk distance is not closely related to aerobic capacity measured either during peak $\mathrm{VO}_{2}$ exercise or during 6-minute of sustained low-level exercise among 321 patients. Although they found that the $\mathrm{VO}_{2}$ provided better prognostic information than the 6-minute walk could not provide.

Both the 6-minute test and incremental exercise testing have been utilized as a suitable measurement of exercise tolerance in individuals with $\mathrm{CHF} .{ }^{21,22}$ Although it is suggested that the 6-minute walk test more closely corresponds to the demand of everyday activities than other types of submaximal testing. ${ }^{23}$ However, it has been shown recently that it is not related to cardiac function and only moderately related to exercise capacity. ${ }^{24}$

McKelvie and colleagues ${ }^{25}$ hypothesized that subjective attitudes, self motivation and mood may have impact on the performance of the test, making it less sensitive to change than the measurement of peak oxygen uptake. This is supported by Opasich and associates, ${ }^{24}$ who suggested that walking performance does not provide prognostic information that can compliment or substitute for that provided by peak $\mathrm{VO}_{2}$ or NYHA class.

Bicycle ergometry may be more energy demanding than walking due to the resistance that the lower limbs have to overcome. Miyamura and Honda ${ }^{26}$ reported that untrained subjects will usually terminate cycle exercise because of quadriceps fatigue at work rates $10 \%-20 \%$ below their treadmill $\mathrm{VO}_{2}$ max.

A study of this nature is essential in order to assist clinicians in quantifying the $\mathrm{VO}_{2}$ max of patients with $\mathrm{CHF}$ during 
an exercise programme in our clinical settings. Since suitable calorimetric equipment are not readily available in many clinics, clinicians may have to rely on the ACSM equations to determine $\mathrm{VO}_{2}$ during supervisied exercise.

The results of this study should be applied with caution, as there are sizeable discrepancies between estimated and measured $\mathrm{VO}_{2}$ because of differences in gait and between the populations being tested from those which the formula for estimating $\mathrm{VO}_{2}$ max was derived. ${ }^{27}$

\section{Clinical implications}

Six-minute walk testing might be useful for the evaluation of functional capacity in patients with $\mathrm{CHF}$ and to monitor the efficacy of pharmacological treatments or rehabilitation protocols in the absence of sophisticated equivalent for measuring expired gas. The higher the distance ambulated the higher the possibility of having a higher $\mathrm{VO}_{2} \max$.

\section{Disclosures}

The authors are aware of no conflicts of interest relevant to this research.

\section{References}

1. Lipkin DP. The role of exercise testing in chronic heart failure. Br Heart J. 1987;58:559-566.

2. Franciosa JA, Pork M, Levine TB. Lack of correlation between exercise capacity and indexes of indexes of resting left ventricular performance in heart failure. Am J Cardiol. 1981;47(1):33-39.

3. Weber KT, Janicki JS. Cardiopulmonary exercise testing for evaluation of chronic heart failure. Am J Cardiol. 1984;53:1447-1450.

4. Wasserman K, Mcllroy MB. Detecting the threshold of anaerobic metabolism in cardiac patients during exercise. Am J Cardiol. 1964; $14: 844-852$

5. Kramer MR, Krivoruk V, Lebzelter J, Liani M, Fink G. Quantitative 15 steps exercise oximetry as a marker of disease severity in patient with chronic obstructive disease. IMAJ. 1999;1:165-168.

6. Janicki JS, Weber KT, McElroy PA. Use of the cardiopulmonary exercise test to evaluate the patients with chronic heart failure. Eur Heart $J$. 1988;9:55-58.

7. Jehn M, Schmidt-Trucksäess A, Schuster T, et al. Accelerometer-based quantification of 6-minute walk test performance in patients with chronic heart failure: applicability in telemedicine. J Card Fail. 2009; 15(4):334-340.

8. Parameshwar J, Dambrink JHE, Sparrow J, et al. A new exercise test for heart failure: use of a self powered treadmill. Br Heart J. 1989; 62:421-425.
9. Fleg JL, Pina IL, Balady GJ, et al. Assessment of functional capacity in clinical and research applications: an advisory from the committee on exercise, rehabilitation, and prevention, council on clinical cardiology. Circulation. 2000;102:1591-1597.

10. Foster C, Pollock ML, Rod JL, et al. Evaluation of functional capacity during exercise radionuclide angiography. Cardiology. 1983;70:85-93.

11. Lucas C, Stevenson LW, Johnson W, Harthy H, Hamilton MA, Walden J. The 6-minute walk and peak oxygen consumption in advanced heart failure: Aerobic capacity and survival. Am Heart J. 1999; 138(4):633-640.

12. American College of Sport Medicine. Guidelines for graded exercise testing and exercise perception. Philadelphia: Lea and Fabiyer; 1980.

13. Cahalin LP, Mathier MA, Semigran MJ, Dec GW, Disalvo TG. The six-minute walk test predicts peak oxygen consumption and survival in patients with advanced heart failure. Chest. 1996;110:325-332.

14. Morales FJ, Matinez A, Mendez M, Agarrado A, Ortega F. A shuttle walk test for assessment of functional capacity in chronic heart failure. Am Heart J. 1999;138(2):292-298.

15. Lipkin DP, Scriven AJ, Crake T, Poole-Wilson PA. Six minute walking test for assessing exercise capacity in chronic heart failure. BMJ. 1986; 292:653-655.

16. Guyatt GH. Use of 6-minute walk as an outcome measure in clinical trials in chronic heart failure. Can Med Assoc J. 1985;132(8):919-923.

17. Mehra MR, Lavie CJ, Milani RV. Predicting prognosis in advanced heart failure: use of exercise indices. Chest. 1996;110:310-312.

18. Cohn JN, Johnson GR, Shabetar R. Ejection fraction, peak oxygen consumption, cardio thoracic ratio ventricular arrhythmias and plasma norepinephrine as determinants of prognosis in heart failure. Circulation. 1985;87:V15-V16.

19. Mancini DM, Eisen H, Kussmaul W, Mull R, Edmunds LH, Wilson JR. Value of peak exercise oxygen consumption for optimal timing of cardiac transplantation in ambulatory patients with heart failure. Circulation. 1991;83:778-786.

20. Sullivan MJ, Higginbotham MB, Cobb FR. Exercise training in patients with severe left ventricular dysfunction. Hemodynamic and metabolic effect. Circulation. 1988;78(3):506-516.

21. Kavanagh T, Myers MG, Baigrie R, Marteus DJ, Sawyer P, Shepherd R. Quality of life and cardiorespiratory function in chronic heart failure, effective of 12 months of aerobic training. Heart. 1996;76:42-49.

22. Keteyian SJ, Levine AB, Brawner CA, Kataoka T, Rogers FJ, Schairer JR. Exercise training in patients with heart failure. A randomized, controlled trial. Annals of Intern Med. 1996;124:1051-1057.

23. Sullivan M, Genter F, Savvides M, et al. The reproducibility of hemodynamic, electrocardiographic and gas exchange data during treadmill exercise in patient with stable angina pectoris. Chest. 1984;86: 375-381.

24. Opasich C, Pinna GD, Mazza A, et al. Six-minute walking performance in patients with moderate to severe heart failure; is it a useful indicator in clinical practice? Eur Heart J. 2001;22(6):488-496.

25. Mc Kelvie RS, Teo KK, Robert R, McCartney K, Yusuf S. Effects of exercise training in patients with heart failure: the exercise rehabilitation trial (EXERT). Am Heart J. 2002;144:23-30.

26. Miyamura M, Honda Y. Oxygen intake and cardiac output during peak treadmill and bicycle exercise. J Appl Physiol. 1972;70:85-93.

27. Franklin BA. Pitfalls in estimating aerobic capacity from exercise time or work load. Appl Cardiol. 1986;14:25-26.

\section{Publish your work in this journal}

The International Journal of General Medicine is an international, peer-reviewed open-access journal that focuses on general and internal medicine, pathogenesis, epidemiology, diagnosis, monitoring and treatment protocols. The journal is characterized by the rapid reporting of reviews, original research and clinical studies across all disease areas.

\section{Dovepress}

A key focus is the elucidation of disease processes and management protocols resulting in improved outcomes for the patient.The manuscript management system is completely online and includes a very quick and fair peer-review system. Visit http://www.dovepress.com/ testimonials.php to read real quotes from published authors. 